\title{
Either/or: Subjectivity, Objectivity and Value ${ }^{1}$
}

\author{
Penultimate draft \\ Katalin Balog
}

"If the doors of perception were cleansed every thing would appear to man as it is, Infinite. For man has closed himself up, till he sees all things thro' narrow chinks of his cavern." William Blake, The Marriage of Heaven and Hell

My concern in this paper is the role of subjectivity in our pursuit of the good. I propose that subjective thought as well as a subjective mental process underappreciated in philosophical psychology contemplation $^{2}$ - are instrumental for discovering and apprehending a whole range of value. In fact, I will argue that our primary contact with these values is through experience and that they could not be properly understood in any other way. This means that subjectivity has central importance in our evaluative life.

I understand subjectivity and objectivity in concepts, thoughts and mental processes in terms of their connection to experience. A concept, thought or mental process is subjective to the degree it is connected to experience; whereas it is objective to the degree it is abstracted away from it. ${ }^{3}$ If, as I argue, experience is required for the apprehension of a sort of value, it stands to reason that the subjective mental process I call ‘contemplation' - which involves voluntary attention to experience , together with subjective thought in the form of observational beliefs about value, are required for reaching a better, fuller, more vivid and accurate understanding of many of the values that enter into our lives. This entails that cultivating subjectivity has great practical significance.

The plan is as follows. First, I provide a preliminary discussion of the subjective/objective distinction, especially as it applies to concepts and thought. Second, I outline the view that a vast array of values is apprehended in experience. Next, I provide an account of contemplation. In the final section, I elaborate on the role of subjectivity in pursuing the good.

\section{Subjectivity and objectivity in concepts and thought}

\footnotetext{
${ }^{1}$ Versions of this paper have been presented at the Pacific APA in 2017, at NYU, Yale and Central European University. I am grateful to these audiences for stimulating discussion. I want to thank for especially helpful comments and criticism Ruth Chang, Camil Golub, Barry Loewer, Howard Robinson and the editors of this volume.

2 I use 'contemplation' in a technical sense to be explained later in the paper.

3 This distinction goes back at least to the philosophies of Descartes and Kant. It has been recently discussed by Brian Loar $(1987,1995,1997,2003)$ and Thomas Nagel $(1974,1979,1986)$, among many others.
} 
I want to note at the outset that by 'subjective' and 'objective' I do not mean the familiar epistemological distinction that associates subjectivity with bias and motivated thought and objectivity with the standards of rationality. In an important article, Thomas Nagel (1979) spells out the difference between subjective and objective concepts in the following way. A concept is subjective if it is closely tied to perceptual or sensory experience. Examples are introspective concepts, such as the concept of feeling cold formed while undergoing the experience, perceptual demonstratives ('that beautiful thing'), or recognitional concepts ('rainbow', 'blood', etc.). Subjective concepts can only be acquired and used by subjects that are familiar with the experiences involved, who know, in Nagel's expression, "what it's like" to have these experiences. A blind person, for example, cannot form a subjective concept of red as it presupposes a familiarity with how red appears.

On the other hand, even blind people can acquire the concept of red as a certain kind of light reflectance. This concept is objective. Objectivity is marked by abstraction from sensory and perceptual sources of information. Concepts like 'citizen', or 'collateral damage' are objective; as are concepts such as 'charge', 'electron', 'logarithm', etc. which are the farthest removed from experiential concepts. Intelligent creatures with a very different sensorium might not share any of our subjective concepts while they could well entertain our more abstract ones. 'Objective' and 'subjective' does not denote a binary difference between concepts; rather, it denotes a continuum that runs from more subjective to more objective concepts, with perceptual demonstratives providing the subjective pole, and the concepts in mathematics and fundamental physics providing the objective pole.

Based on this distinction, we can draw a further distinction between subjective and objective thought: a thought is subjective or objective corresponding to the degree that it employs subjective or objective concepts. For example, experiencing beauty might prompt us to make the subjective observational judgment "that is beautiful" in the same way experiencing red prompts the subjective observational judgment "that is red". On the other hand, thinking of red in scientific terms is an example of objective thought.

Recently Laurie Paul, in her book Transformative Experience, argued persuasively that engaging in subjective thinking is indispensable for evaluating possible scenarios, and that because of this, we 
need to substantially rethink our understanding of decision making. By placing my ideas in the context of Paul's work on decision making, I will be better able to explain the scope of my project. Paul introduces the concept of transformative decision - a decision at least one of whose outcomes involves a "transformative experience". A transformative experience is both epistemically transformative in that it involves experience hitherto unknown to the subject, which, as a result of undergoing the experience, will become familiar to them; and personally transformative in that it substantially changes the subject's values and aspirations. The more radically life-altering the decision is - think of, for example, having a child - the harder to imagine what life will be like afterwards, the harder it is to have a subjective conception of what life with a child involves, the more likely it is that the experience is both epistemically and personally transformative. Ahead of the decision, Paul says, one has no way of forming a subjective concept of the emotional bond that will develop, or of the intense focus on the welfare of one's child that will replace one's former freewheeling, self-centered existence. Moreover, Paul thinks $(2015$, p.12) that experience has subjective value, grounded in the phenomenal character of the experience, which needs to be taken into account in decisions and which, similar to the phenomenal character of the experience, can only be properly grasped - for the purposes of authentic decision making - in a subjective way. This has particular consequences for transformative decisions.

In the case of transformative decisions, she argues, one cannot be both rational and authentic. Authenticity requires that one is able to grasp the relevant subjective values from one's own point of view, that is, in subjective terms that alone can fully reveal their significance for the subject. A rational assessment of the values of outcomes in a transformative decision would have to include in its purview the subjective values of the experiences involved. But even if one were able to receive objective information about those subjective values (say, from statistical evidence) and make a rational decision, that decision would not be authentic in the absence of an appropriate subjective grasp of the values at stake.

I share Paul's concern with the role of subjective thought in grasping values. But my focus is not on decision making itself but on the role subjective thought plays in the process of coming to know what one values - a precondition of making rational decisions, and in general, of identifying and moving towards meaningful projects and relationships. As Talbot Brewer (2009) observes: 
[Some] conceptions [of decision making] encourage the thought that one's outlook on value ought rationally to be complete and determinate before one begins the work of deliberation about particular cases. They provide no insight into the most fundamental work of deliberation, which is the formation and revision of a tenable conception of the good. Instead, they reduce deliberative rationality to skill in estimating probabilities and performing calculations. But the work of proper deliberation is not the work of an accountant. It is the work of a seeker after the good, and it often requires a fresh straining to form a more just and palpable sense of the goods bearing on one's ongoing activities. (p. 103)

Paul thinks about experience as itself having what she calls subjective value. Eating kiwi is a good thing, at least partly because the experience of eating kiwi has value for me. I suggest that the main contribution of the experiential life to the evaluative life is not that experience itself is valuable, but that it represents, in addition to perceptual properties, value properties as well. We come to appreciate the value of things, activities and people, their appeal, their depth and significance, etc. - wholly or partly - in our everyday phenomenal experience. ${ }^{4}$ This is not to deny that experience has value in

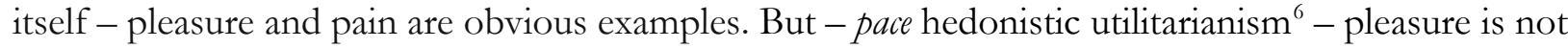
the sole, or even the main kind of good in the world. It is the flower that is beautiful, not my experience of it, though the experience has some value in itself as well.

\section{Value and experience}

"Contemplated by different people, [the] same glass can be a thousand things, however, because each man charges what he is looking at with emotion, and nobody sees it as it is but how his desires and state of mind... see it.” (Luis Buñuel 1958)

"All primordial comportment toward the world....is a primordial emotional comportment of value-ception." (Max Scheler 1916/1973, p. 229)

I will now make some fairly general remarks about value and experience. I am going to be only as specific as is necessary to establish the significance of subjectivity thought in our evaluative lives. I propose that in perception, our experience represents evaluative properties as well as strictly perceptual ones. There is a distinction between the perceptual/sensory aspects of experiential

\footnotetext{
${ }^{4}$ Johnston (2001) has a similar view. See also Noordhof 2018.

${ }^{5}$ By phenomenal experience here I mean sensory, perceptual as well as emotional states. Though I think intentional states such as beliefs, etc. have their own distinctive phenomenology they don't count as experiences in the way I intend to use the term here.

${ }^{6}$ For a powerful argument against hedonism see Robert Nozick's (1974).
} 
content, and its affective aspects. More is presented in, say, a visual experience than the standardly agreed upon perceptual properties, such as color, shape, illumination, motion, their co-instantiation in objects, etc. ${ }^{7}$ The flower appears to me pale blue, fragrant, with a sharply defined shape; it also appears delicate, refreshing and delightful. Such sensuous features give the world its significance at the most fundamental level. Freshness or beauty is as much part of the content of my experience of the flower as is its color and shape. In experience, we grasp the fully determinate versions of determinables such the beautiful, the kitschy, the sublime and the horrific, the appealing and repulsive. Intuitively, such values can only be grasped by people who have experienced instances of them. Johnston ${ }^{8}$ calls these the "inherently sensuous" values. Some philosophers hold that in addition to the inherently sensuous ones, broadly moral values, such as kindness, probity, or shiftiness are also represented in perception. ${ }^{9}$

Some philosophers, on the other hand, hold that values are represented not in sensory/perceptual experience, but in the emotions that attend them. This is most plausible for the moral realm, with e.g., anger, resentment, or love representing their objects as offensive, despicable, or desirable. ${ }^{10}$ But one might argue that even sensuous values, such as beauty or ugliness are represented in the attending "aesthetic emotions" and not in the perceptual experience itself.

It is hard to adjudicate this question as perception and affect is closely intertwined in experience. Though I prefer the view on which perceptual states possess an affective component - rather than merely occur concomitant with emotions - I will be non-committal about whether values are represented in perception, emotion, or both. My only claim is that there is, as Scheler calls it, 'valueception', i.e., that value is represented experientially, in the broad sense that includes emotions and sentiment. The evaluative aspect of experience is often quite salient. But even when that is not the case, even when it is not obvious or easy to discern, it is still present. Perhaps all normal experience is evaluative - things don't tend to be experienced as entirely neutral. ${ }^{11}$

\footnotetext{
${ }^{7}$ For arguments that perceptual experience represents "higher level" properties, such as natural kinds, or causal relations, see Siegel (2006), Block (2014).

${ }^{8}$ Johnston (2001), p. 182.

${ }^{9}$ McDowell (1985), Johnston (2001), Audi (2018), Noordhof (2018).

10 See, e.g., Döring (2003).

${ }^{11} \mathrm{I}$ also wish to remain neutral about a host of meta-ethical questions about the nature of value. Any meta-ethical position that is compatible with the claim that value is represented in experience - and, as will argue later, that it could not be represented in thought in the absence of evaluative experience - will do.
} 
Are all values apt to be represented in experience? For example, can values such as the revelatory power of conceptual art, or the wrongness of perjury experienced? Take the case of witnessing perjury while - through simultaneous fact checking - one is also aware that this is indeed perjury. There might be - if one is well-brought up - an immediate, felt sense of wrongness to one's apprehension of the situation. But is this "felt sense" purely an experience? On the one hand, it might be that a conceptual grasp of the fact that one is witnessing perjury penetrates one's (perceptual or emotional) experience ${ }^{12}$, and produces a phenomenal representation of wrongness. ${ }^{13}$ But it might also be that the experience by itself does not represent the wrongness of perjury, that additional conceptual thought is required for its grasp. ${ }^{14}$ I will not take up this issue. Either way, I maintain that a broad range of values are represented in experience. ${ }^{15}$

But is experience really required for grasping the sensuous values? Could it not be adequately grasped in objective thought alone? To the degree that this was the case, subjective thought about values might be dispensable. To bring the question into focus, consider the following thought experiment. In a twist on Frank Jackson's famous Knowledge Argument ${ }^{16}$, imagine that there is a person - we might call her Insensate Mary - whose experience, though it has the same sensory/perceptual content as ours, lacks an affective aspect altogether. When she sees a roadside accident, she has no "gut reaction" to it: she feels no aversion, no horror, no sadness, or, as the case might be, no morbid curiosity.

The thought-experiment relies on the idea that we can conceive of an experience that has perceptual content but lacks affective content altogether. It seems likely that these aspects can vary somewhat independently. We all experienced walking the same streets or looking at the same objects experiencing them wildly differently depending on our mood, or general state of mind. What was

\footnotetext{
12 For an account of cognitive penetration in the moral case, see Cowan (2015).

${ }^{13}$ One of the main arguments for the perceptual representation of higher-level properties is the Contrast Argument (see Siegel (2006). For an application in the aesthetic case see Stokes 2018.

${ }^{14}$ Lyons (2018), e.g., thinks that this felt sense is actually something post-perceptual, a perceptual seeming state which has experiential phenomenal character and conceptual content.

15 There is good reason to think that the range of values that can be represented in experience is fairly wide. It is fairly plausible to assume that the many species of mammals that can discern love, harm, danger, untrustworthiness or unfairness - and which are capable of empathy, reconciliation or disapproval (see De Waal 2006) - do so through conscious perception or emotion rather than conceptual thought. ${ }^{16}$ Jackson (1982).
} 
drab and uninspiring one day might be exciting another day. To take an example that is more directly relevant, consider the way morphine affects pain: it apparently it leaves the sensory content intact but removes the affective component, the awfulness of pain. Whether or not that is indeed the case, however, and so whether or not the two aspects of experiential content can really come apart, it seems possible to conceive that they do.

Unlike Jackson's Mary, Insensate Mary does not have superhuman knowledge in objective terms to ponder the abilities of such a creature would be irrelevant for my inquiry which centers on the lives of humans. Insensate Mary is quite normal in her abilities to reason in objective terms but unlike Jackson's Mary - has never experienced the myriad determinate ways in which something can be beautiful, or scary, or desirable. She cannot know about these things from the first person perspective, she cannot think about them subjectively.

Could it turn out that these values are not "inherently" sensuous, in other words, that she could still form some other, objective conception of them, adequate for the purposes of practical engagement? This doesn't seem to be possible. Take for example an artist, Insensate Pollock. Just as his thinking about color needs to be based on his experience of color - a blind painter can't have grasp of color adequate for their practical engagement of it on canvas - he cannot be insensate either. Never having experienced the "push and pull" of colors, shapes and textures, it seems he cannot produce art - except by chance.

Here is why. Suppose that Mary could somehow form, on the basis of third person information, the concept beauty* referring to beautiful things. It seems clear that it would not be a genuine value concept, fit for practical activity. Her evaluations of beauty would lack authenticity, the special first person grasp we have of the sensuous values. Authenticity is required not only for a proper appreciation of value, but also for a proper engagement with it. If she were to seek out beautiful paintings, it would not be driven by her response to the intrinsic value of beauty and so, in a certain way, it would be inexplicable. ${ }^{17}$ Sensuous values can be authentically, properly grasped only through subjective experience - through the visceral experiences of attraction and recoil they produce in us. Their authority - their power to motivate - lies in the affect they produce in us. Affective

\footnotetext{
17 Paul (2015) makes this point in connection with the importance of authenticity in transformative decisions.
} 
insensitivity cannot be compensated by objectivity.

As a matter of fact, even in the case of normal subjects, forming an objective conception of some manifestation of sensuous value is, at least in some respects, defective for the purposes of practical life. Take a case where you form a second-hand conception of some manifestation of beauty. Suppose you had a twin whose tastes and evaluative dispositions with regard to the sensuous values are identical to yours. Even so, it would not do you much good to defer to her to make beauty judgments, say, about a work of art you haven't seen, or a new garden in the neighborhood that you don't want to bother to visit. Those judgments wouldn't be authentically yours as they wouldn't reflect your actual take on the world. Moreover, since such deferential judgments would not be based in a sensuous grasp of an instance of a fully determinate version of the beautiful, you could only make a fairly general appraisal of the attractions of the garden or the art. Finally, such appraisals only have an indirect claim on you compared to the instances of value you encounter yourself.

How about the more abstract, objective value concepts such as justice or fairness? I suggest that Insensate Mary - lacking a sensuous appreciation of the world - lacks the necessary basis to form any evaluative concepts at all. I think that nothing could have significance or meaning for a creature who lacked basic experiences of sensuous value. I will discuss this in a little more detail later.

\section{Contemplation and subjective thinking}

"the way... is to become subjective, ... to become subject." (Kierkegaard, Concluding Unscientific Postscript) ${ }^{18}$

In the following pages, I develop an account of subjective thought to provide a psychological framework in which to understand what Brewer calls the "formation and revision of a tenable conception of the good". In many of his religious writings, ${ }^{19}$ Kierkegaard discusses, either implicitly or explicitly, the difference between a subjective and objective thinker. ${ }^{20}$ He uses the term 'subjective' and 'objective' to demarcate more than just a difference in two styles of conceptual thought. He seems to imply that mere conceptual thought - even subjective conceptual thought -

\footnotetext{
18 Kierkegaard (1846/1992), p. 109.

${ }^{19}$ See, especially, Kierkegaard (1846/1992).

${ }^{20}$ Kierkegaard never explicitly defines these terms. I introduce what I think is a plausible elaboration of what Kierkegaard had in mind.
} 
doesn't make a thinker subjective. A subjective thinker cultivates subjective conceptual thought rooted in a mental process that I, for lack of a better word, will call contemplation.

Contemplation, in the sense I intend, is more than just having experience; not all experiencing counts as contemplation. It involves a distinct process that is, like conceptual thought, partly voluntary: the deployment of attention to the content of one's experience, for example, to the colors and textures of the ocean while swimming, or to the haunting melody of a song. Experiences being non-conceptual representations ${ }^{21}$ contemplation does not involve reasoning but associations among memories, images, fantasies and thoughts. In contemplation, experience is "held" in attention and is explored without a particular goal in mind. This is different from other forms of attention deployed in thought or perception in which it is fast moving and is task oriented.

Contemplation happens in small ways every time we stop to appreciate the world as we experience it, every time we are present for what is happening in a deliberate fashion, rather than breezing through in automatic pilot (or be absorbed in thought to the exclusion of experience). Examples include appreciation of nature, reflection on art, or paying attention to other people in an experiential sort of way (as opposed to just thinking about their words). Contemplation is separate from conceptual thought, but it provides the basis for subjective conceptual thought, and in particular, the basis for conceptual thought about value. At the same time, conceptual distinctions made on the basis of experience serve to enhance and enrich our experience, as, for example, in the case of wine tasting. Though values - like taste - are often perceived in experience, they are not always readily so - their discernment requires patient contemplation and subjective conceptual thought. Contemplation, contrary to a widely held misconception, does not necessarily mean an inward focus on experience itself, a drawing back of one's attention to the self. It can just as well consist in paying attention to the objects of experience, through the experience, rather than through conceptual thought.

\footnotetext{
${ }^{21}$ Gareth Evans (1982) introduced the term 'conceptual vs. 'non-conceptual' content into contemporary philosophical discussion where the latter characterizes perceptual and certain other mental states. His idea was that these states are like thoughts in so far as they are representational. But they are unlike thoughts in that where a thought, say that the cat is bungry, has a conceptualized content composed out of the concepts cat and is hungry, a person's visual perception of the cat is not composed out of concepts and represents the cat in some other way.
} 
Contemplation can happen in formalized contexts such as meditation ${ }^{2223}$ and certain kinds of psychotherapy as well. ${ }^{24}$ Part of the aim of meditation and psycho-therapy is to impart skills of contemplation that can be exercised in one's daily life in one's ongoing perceptual engagement with the world.

In extreme cases, there might be temporary states of pure contemplation, or states of pure conceptual thought, ${ }^{25}$ but normally the two intermingles and interacts. A thinker is subjective, in the way I propose to use the term, to the degree that they engage in contemplation, and that their conceptual thought tends toward the subjective side. A thinker is objective to the degree that they refrain from contemplation and that their conceptual thought tends toward the objective side.

People differ in their style of thought. Some engage the world mostly by thinking conceptually and tend to pay little attention to their experience. On the other hand, a highly contemplative person, for example, an artist, or a monk, is attuned to their experience and their conceptual thought is mostly subjective. Most people are somewhere in between those two extremes. In the novel The Brothers Karamazov, two of the brothers, Ivan and Alyosha share the Karamazov "sensuality", a certain intensity of experience; but Ivan reacts by repressing his feelings and withdrawing into the stance of a cynical, witty observer, while Alyosha cultivates his inner life through religious training, and views the abstractions of politicians and "learned people" as "wicked nonsense."

Thought is understood primarily as conceptual. I want to stress that there is another mode of thought - experiential and non-conceptual - that plays an important role in our psychology. While its best-known practices - meditation and psycho-therapy - are generally understood as tools for stress management or relief from psychological pain for those in need, I suggest that contemplation has a broader role to play. In the next section, I elaborate on some of the ways contemplation is essential in our evaluative life.

\footnotetext{
22 The two main kinds of meditation involves focused attention, usually on the breath or parts of the body, and open monitoring, which involves an evenly hovering attention over the field of conscious experience. See Lutz et al. (2008) for the distinction.

${ }^{23}$ See, e.g. Lutz et al. (2015), and Grossenbacher et al. (2017) for an account in cognitive neuro-science of various contemplative practices.

24 Various forms of psycho-analysis encourage this kind of thinking, e.g., in "free association" (Freudian analysis), or "active imagination" (Jungian analysis).

25 A scenario like that is described in Dennett (1978) involving complete sensory deprivation.
} 


\section{Reasons to cultivate subjectivity in the pursuit of the good}

\section{Cultivating subjectivity to have a better grasp of values}

In Sinan Antoon's ${ }^{26}$ novel on the Iraq war, The Corpse Washer, the protagonist describes his job in this way:

If death is a postman, then I receive his letters every day. I am the one who opens carefully the bloodied and torn envelopes. I am the one who washes them, who removes the stamps of death and dries and perfumes them mumbling what I don't entirely believe in. Then I wrap them carefully in white so they may reach their final reader - the grave.

The corpse washer, as a function of his occupation, attains a more direct, subjective perspective on war's destruction than those who learn about it from the news. He sees and contemplates, over and over, the bodies, maimed, drained of life; he touches them, his seeing and sensing intertwined with his terror. His contemplation reveals not just the gun-shot wounds, corpses, and destruction but also their particular awfulness. Such perception of dreadfulness forms the basis of further associations it brings up related memories and images of friends and family killed, maimed and exiled. Attention to all this throws the dreadfulness of war and violence into sharp relief, so it can be reflected and acted upon.

Sensibility can be trained in many ways - art, music, mountain climbing, even corpse-washing are ways to increase sensibility. It proceeds by joining contemplation with conceptual elaboration; the experience of an arpeggio is different for one who has the concept and for one who doesn't, war's ravages are different for someone who has the experience and vocabulary to grasp its gruesome details than for someone who doesn't. The more attention one pays, and the greater conceptual sophistication one has, the more fine-grained one's understanding of the world through experience, and the more fine-grained one's discernment of the values manifesting in it.

The corpse washer's experiences lead him to grasp the war's significance in ways that separates him from people who hear about it from the news. This kind of difference in understanding is manifest, for example, in debates between survivors of mass shootings and politicians in charge of gun laws. The corpse washer or the survivor thinks about war and violence subjectively, with a thorough understanding of the stakes involved, while most politicians, despite the occasional dramatic footage,

\footnotetext{
26 Antoon (2014).
} 
think about it in objective, ${ }^{27}$ impoverished, sanitized terms such as "civilian casualty" or "collateral damage". Both ways of thinking have their virtues and vices. Politicians are expected to weigh competing considerations in an impartial manner, which requires a certain level of abstraction. Survivors, however, understand the stakes involved more thoroughly than people who never experienced violence.

\section{Overcoming abstraction, bias, and self-deception}

Contemplation, however, is difficult. It is often difficult to become aware of the affective valence of experience as there are many other things that claim one's attention. Moreover, contemplation requires a certain amount of self-denial: it requires the acceptance of one's experience of the world as it is, with all the pain as well as joy it contains, instead of seeing it in the light most pleasant and flattering for the self. This runs against strong forces in human nature. Most commonly, one turns one's back on subjectivity to escape from pain. As Freud has described, the mind has powerful builtin mechanisms that helps expunge unwanted experience from consciousness: repression, dissociation, sublimation, etc. In more ordinary cases, one simply takes a step back to consider the "facts" rather than dwell on the experience.

Even small discomfort can prompt one to turn away from experience. If I pass a homeless person on the street, I might tune out so as not to feel any pangs of guilt about not having contributed. We react strongly to anything that challenges our own self-image. What needs to be learned, as Iris Murdoch has observed, ${ }^{28}$ is "how real things can be looked at and loved without being seized and used, without being appropriated into the greedy organism of the self." Contemplation requires the skill to direct attention to what's going on in an impartial way, without distortion; which is perhaps most difficult when it comes to understanding and empathizing with others.

There are many ways that different cultures developed to foster this kind of self-discovery. The Chinese book of divination, the I Ching, guides decisions not by providing practical solutions, but by offering an opportunity to contemplate one's experience, in memory and imagination, in an

\footnotetext{
${ }^{27}$ I want to remind the reader that by "objective" thought I don't mean unbiased or rational thought - I simply mean a kind of thought that tends toward abstraction.

${ }_{28}^{2}$ Murdoch (1970), p. 23.
} 
open-ended manner. Buddhist meditation practice is based on the understanding that contemplative engagement requires considerable effort. It provides training in sustaining awareness of experience without turning away from any aspect of it or trying to change it to something else. This has to be achieved in the face of the fact that conceptual thought is more likely to command one's attention, and often in its less fruitful displays, like rumination, day-dreaming and the like driven by various agendas. Both traditions hold that to fully realize the meaning of one's life and to be able to best align with the good in it one needs to live a contemplative life.

It might be objected that one can live a full life dedicated to values and ideals without dwelling on subjectivity at all. Value concepts differ in their subjectivity; some are more abstract than others. 'Beauty' or 'love' is subjective ${ }^{29}$; 'vulgarity' is more objective; 'injustice' is more objective still. One can perhaps ignore sensuous values and still have a rich evaluative life, have enough aspirations to occupy one for a lifetime, dedicated to promote justice, equality, freedom.

Here is why objective thought, when it is not accompanied by a subjective engagement with value, is not enough. Any capacity to see the world through an evaluative lens - as I suggested earlier regarding the case of Insensate Mary - is grounded in experience. To the degree that one's evaluative life centers around abstract concepts, while having dimmed or deadened any perception of value, one has cut the vital source of one's connection to value. Life becomes cerebral and dull, one's self-knowledge lacking. Thinking about matters of value in abstract terms conceals the significance of the issues involved, as in the case of, e.g., talk about "collateral damage". Just as Insensate Mary's concept beauty* is defective for the purposes of practical life, abstract conceptions of value such as "social justice", when not connected to vivid experiential conceptions of, say, pain, injury, disrespect, etc., are defective as well. They do not reveal why one should care at all. ${ }^{30}$

\footnotetext{
${ }^{29}$ Love has both subjective and more complex, more objective conceptions; I will skip over that here.

${ }^{30}$ Indeed, contemplation may be a last resort for moral agency when normal moral thought had lost its purchase, as in situations of extreme dehumanization. In the film Son of Saul (László Nemes, 2015) the protagonist Saul, a prisoner in Auschwitz, is first shown in a deadened state of being. In the opening scenes he hardly pays attention to any of the carnage happening around him - he is just doing his tasks in a mechanical way. He regains a sense of agency amidst the general chaos after witnessing, with his attention focused on it like a laser beam, the murder of one particular person, who he later declares to be his son (the movie is ambiguous about whether that is so). He now has a mission: to try to arrange a proper funeral.
} 
Moreover, basing one's aspirations on objective conceptions of value alone can prepare the ground for self-delusion and compulsive action. The dictum 'know thyself" doesn't just call you to find out about your capacities and dispositions, habits of thought, etc., though that is certainly part of it. It also calls for a more thorough familiarity with how you experience the world and yourself: with your perceptions of the world, sensations of your body, your emotions, memories, and fantasies as well. Only this way can you find out what you really want - which of the goods that you perceive in the world really matter for you. For example, you might not realize until you start paying more attention that you like to be with a person very much even though the person's virtues are not what you "officially" care about most. Figuring this out requires conceptual thought; but it would not be possible without close attention to your experience. Objective conceptual thought cannot entirely replace contemplation and subjective thought in a pursuit of the good.

What about misrepresentation of value in experience? Does careful contemplation guarantee freedom from self-deception? Perhaps there are some sensuous values, such as beauty or ugliness, attractiveness or repulsiveness, etc. whose exemplification is wholly dependent on the experiences of the subject. In that case, there could be no gap between what the subject experiences as beautiful and what is really beautiful for the subject. One would still need to be attentive so as not to make a mistake by inattention if one aspires to orient towards the sensuous goods; however, once proper attention is deployed, there would be no possibility of correction based on further evidence. But this is not true generally; there are kinds of value that are sometimes misrepresented in experience. I can, for example, be mistaken in my experience that someone is shifty, or honest, or vulgar. This means that the contemplation of experience is just the first step in a process of discovery, a "straining" to come to an accurate grasp of the values involved. A plain example is the way emotions and memories can distort experience; jealousy, for example, can prevent one from seeing the virtues of another person accurately. Contemplating not just the experience of this person as, say, being vulgar, but also the inner landscape that shades one's perception of this person in unflattering ways, paves the way to form better and more just conceptions of their behavior - of seeing them as they are. ${ }^{31}$

\footnotetext{
${ }^{31}$ Murdoch (1970) p. 32 discusses a case like this involving a mother and a daughter-in-law. Throughout the book, she emphasizes the moral relevance of the inner life in coming to a more accurate perception of value. If successfully executed, "selfish concerns vanish, nothing exists except the things which are seen."
} 


\section{Cultivating subjectivity and appreciating the world}

According to the Buddhist and Daoist tradition, contemplation fosters appreciation. The point is not just that contemplation discloses goods to pursue - it also leads to valuing life as such. It can bestow vividness and meaning on ordinary, boring, everyday activities; only it can create the sense that one's life has touched the world. As D.T. Suzuki (1956) remarks:

"Life, as far as it is lived in concreto, is above concepts as well as images. To understand it we have to dive into and come in touch with it personally; to pick up or cut out a piece of it for inspection murders it; when you think you have got into the essence of it; it is no more, for it has ceased to live but lies immobile and all dried up." (D.T Suzuki (1956, p. 58)

The following poem by Czeslaw Milosz expresses the power of contemplation to create appreciation for life. The poem itself needs to be contemplated rather than just thought about to yield its meaning:

At the entrance, my bare feet on the dirt floor, Here, gusts of heat; at my back, white clouds, I stare and stare. It seems I was called for this: To glorify things just because they are. ${ }^{32}$

To unlock the poem, it is necessary to contemplate the feelings, memories, and images evoked by it. Such contemplation captures the deep structure of experience; uncovering its resonances and dissonances, its associative structure. Only then - and only partially - can one's understanding be put to words and thought about conceptually. The poem's imagery mixes with experiences you remember, creating the sense of awe it expresses, a sense of the value of ordinary life, discovered through a deep awareness of experience.

\section{Cultivating subjectivity and "slow decisions"}

"I began to have an idea of my life, not as the slow shaping of achievement to fit my preconceived purposes, but as the gradual discovery and growth of a purpose which I did not know" (Marion Milner, A life of one's own)

"The task of attention goes on all the time and at apparently empty and everyday moments we are

32 From “Blacksmith shop", by Czeslaw Milosz, in Provinces, The Ecco Press, 1991. 
'looking', making those little peering efforts of imagination which have such important cumulative results." (Murdoch 1970, p. 22)

"moral change and moral achievement are slow...the exercise of our freedom...is a small piecemeal business which goes on all the time and ... not something that is switched off in between the occurrence of explicit moral choices." (Murdoch 1970, p. 33)

Decisions can be framed more objectively, or more subjectively. One might decide between career choices by weighing them in relatively abstract terms, such as the pay involved, the security the job offers, opportunities for learning, etc. Alternatively, one might frame the decision, at least in part, in terms of an assessment of what it might be like to work in those occupations. Such a framing allows a more nuanced sense of the values involved as well as an authentic appreciation of them. ${ }^{33}$

Objective deliberation, with its straightforward considerations of value and chance of success is relatively fast. It doesn't take weeks or months to complete. On the other hand, when value judgments are made in isolation from relevant experience, they often have limited power to change behavior, as the fate of many a New Year's resolution shows. Subjective deliberation, on the other hand, takes time. In a slow, subjective decision process one allows oneself to live with the question for a while, to dwell in experience long enough for one's feelings about the decision to emerge. How one wants to spend one's life and whom one wants to spend it are discoveries rather than simply a matter of rationally appraising the known parameters of a situation.

Sometime, even when all the relevant facts are known, it takes time to make a decision that feels appropriate. Such a decision can happen as a result of a familiar consideration presenting itself over and over again - as, for example, in the case of having to deal with an untrustworthy friend or lover. You might have understood, in an abstract sense, what is happening, and may have been at the point

of trying to draw the consequences. But your decision never stuck, it never felt quite right. However, once you have gradually allowed yourself to fully experience your friend's behavior - putting aside

\footnotetext{
33 Paul (2015) emphasizes only such decisions count as authentic.
} 
any effort to find excuses - you will likely come to a point where you can act. As Kierkegaard puts it in Either/Or,

Ask yourself, and continue to ask until you find the answer. For one may have known a thing many times and acknowledged it ... and yet it is only by the deep inward movements, only by the indescribable emotions of the heart, that for the first time you are convinced that what you have known belongs to you ... for only the truth that edifies is truth for you.

The crucial part of decision making is the process of discovery that precedes it. Whereas rational choice theory provides an algorithm for comparing choices once one knows their value, it is contemplation that helps determining what those values are, and making them vivid to pull one with enough motivating force. As Dostoyevsky says, in Notes from the Underground, "reason is a good thing, that can't be disputed, but reason is only reason and satisfies only man's intellectual faculties, while volition is a manifestation of the whole of life."

Paul casts doubt on the relevance of decision theory as a useful model for transformative decisions. My approach signifies another way in which taking subjective experience seriously suggests a shortcoming of rational decision theory as a model for actual decision making. Decision theory treats knowledge of values as readily available; or at least has nothing to say about how to obtain it. In fact, finding out what one values is the most difficult, and most crucial part of decision making.

I have argued that value discourse benefits from incorporating the notions of contemplation and subjective thought in philosophical psychology. The upshot is that cultivating subjectivity is an important and underappreciated aspect of the pursuit of the good. According to Kierkegaard, it is the most important of all.

\section{References:}

Audi, Robert (2018). "Moral Perception Defended", in Evaluative Perception, (eds. Bergqvist, A. \& Cowan, R.), Oxford University Press.

Antoon, Sinan (2014). The Corpse Washer, Yale University Press.

Barnard, PJ and Teasdale, J (1991) Interacting cognitive subsystems: A systemic approach to cognitive-affective interaction and change, Cognition and Emotion, 5(5). 
Barnard, PJ, Duke, DJ, Byrne, RW \& Davidson, I (2007). Differentiation in cognitive and emotional meanings: an evolutionary analysis. Cognition and Emotion 21(6) 1155-1183.

Bergqvist, A. \& Cowan, R. (2018). Evaluative Perception, Oxford University Press.

Block, Ned (2014). "Seeing-As in the Light of Vision Science" Philosophy and Phenomenological Research, Volume 89, No. 3. 560-572. DOI: 10.1111/phpr.12135

Brewer, Talbot (2009), The Retrieval of Ethics, Oxford University Press.

Buñuel, Luis (1958). “The Cinema, Instrument of Poetry”, in Cuadermos de la Universidad de México, 4, December 1958.

Cowan, R. (2015). "Cognitive Penetrability and Ethical Perception”, Review of Philosophy and Psychology, 6/4:665-82.

Dennett, Daniel, (1978). 'Where am I?’, in Brainstorms, MIT Press.

Döring, S.A. (2003). “Explaining Action by Emotion”, Philosophical Quarterly, 53/211:214-30.

Dostoevski, Fyodor (1993). Notes from the Underground (trans. Richard Pevear and Larissa Volokhonsky), Vintage Books.

Evans, G. (1982). The V arieties of Reference, Oxford: Oxford University Press.

Jackson, F. 1982. "Epiphenomenal Qualia”, Philosophical Quarterly 32: 127-36.

Johnston, M. 2001. "The authority of affect", Philosophy and Phenomenologicall Research, 68: 181-214.

Grossenbacher, P. G., \& Quaglia, J. T. (2017). "Contemplative cognition: A more integrative framework for advancing mindfulness and meditation research", Mindfulness, 8(6), 1580-1593. DOI 10.1007/s12671-017-0730-1

Kierkegaard, Soren (1846/1992). Concluding Unscientific Postscript to Philosophical Fragments, Princeton University Press.

Loar, Brian, 1987. 'Subjective Intentionality', Philosophical Topics, 1:89-124. Reprinted in Consciousness and Meaning: Selected Essays by Brian Loar (eds. Katalin Balog and Stephanie Beardman), Oxford University Press, 2017.

Loar, Brian, 1995. 'Reference from the First-Person Perspective', Philosophical Issues: Content, 6: 53-72. Reprinted in Consciousness and Meaning: Selected Essays by Brian Loar (eds. Katalin Balog and Stephanie Beardman), Oxford University Press, 2017.

Loar, Brian, 1997. "Phenomenal states", in The Nature of Consciousness, (Block, Flanagan, Güzeldere, eds.), MIT Press, pp. 597-616 (revised version of Loar 1990). Reprinted in Consciousness and Meaning: Selected Essays by Brian Loar (eds. Katalin Balog and Stephanie Beardman), Oxford University Press, 2017.

Loar, Brian, 2003. 'Transparent Experience and the Availability of Qualia, in Q. Smith \& A. Jokic (eds), Consciousness: New Philosophical Perspectives. Oxford University Press, 77-96. Reprinted in 
Consciousness and Meaning: Selected Essays by Brian Loar (eds. Katalin Balog and Stephanie Beardman), Oxford University Press, 2017.

Lutz, A., Slagter, H. A., Dunne, J. D., \& Davidson, R. J. (2008). Attention regulation and monitoring in meditation. Trends in Cognitive Sciences, 12(4), 163-169. doi:10.1016/j.tics.2008.01.005

Lutz, A., Jha, A., Dunne, J., Saron, C. (2015). "Investigating the phenomenological matrix of mindfulness-related practices from a neurocognitive perspective", American Psychologist, 70(7), 632-658. http://dx.doi.org/10.1037/a0039585

Lyons, Jack (2018). "Perception and Intuition of Evaluative Properties", in Evaluative Perception, (eds. Bergqvist, A. \& Cowan, R.), Oxford University Press.

McDowell, J. (1985) 'Values and Secondary Qualities', in T. Honderich (ed.) Morality and Objectivity, London: Routledge and Kegan Paul, 110-29.

McDowell, J. (1994). Mind and World, Cambridge, Mass.: Harvard University Press.

Milner, Marion (1934/2011). A life of one's own, Routledge.

Murdoch, Iris (1970). The Sovereignty of Good. Routledge and Kegan Paul.

Nagel, Thomas (1974). What Is It Like to Be a Bat? Philosophical Review 83:435-50.

Nagel, Thomas (1979). Subjective and objective, in Mortal Questions. Cambridge University Press, 207-222.

Nagel, Thomas (1986). The View from Nowhere. Oxford University Press.

Noordhof, Paul (2018). "Evaluative perception as response dependent representation”, in Evaluative Perception, (eds. Bergqvist, A. \& Cowan, R.), Oxford University Press.

Nozick, Robert (1974). Anarchy, state, and utopia. New York: Basic Books. pp. 42-45.

Paul, L. (2015). Transformative Experience. Oxford University Press.

Scheler, Max (1916/1973). Formalism in Ethics and Non-Formal Ethics of Values: A new Attempt Toward the Foundation of an Ethical Personalism (Northwestern University Studies in Phenomenology and Existential Philosophy), Northwestern University Press.

Searle, John. 1992. The Rediscovery of the Mind. Cambridge: MIT Press.

Siegel, S., 2006. "Which Properties are Represented in Perception?” in In Perceptual Experience, T. Gendler Szabo and J. Hawthorne (eds.), Oxford: Oxford University Press, 481-503.

Stokes, Dustin (2018). "Rich Perceptual Content and Aesthetic Properties", in Evaluative Perception, (eds. Bergqvist, A. \& Cowan, R.), Oxford University Press.

Suzuki, D.T. (1956). Zen Buddhism. Doubleday Anchor Books.

De Waal, Frans (2006). Primates and Philosophers: How Morality Evolved, Princeton University Press. 